\title{
Dynamics of the guideway system founded on casting compound
}

\author{
Bartosz Powałka • Tomasz Okulik
}

Received: 31 December 2010 / Accepted: 13 June 2011 /Published online: 30 June 2011

(C) The Author(s) 2011. This article is published with open access at Springerlink.com

\begin{abstract}
The work presents a new technology for the assembly of ball guideway systems which involves the use of a thin layer of a casting compound. The experimentally verified simulation research presented in the work indicates that the use of the casting compound between the guide rail and the bed of the machine tool positively influences the dynamics of the system. The paper is concerned with the comparison between the new solution with the guide rail assembly technology presently in use on the basis of a guideway system consisting of a body and a milling table. The dynamics was compared with the use of a frequency response function which had been determined in an impulse test. The proposed solution is characterised by a higher dynamic stiffness, which may directly influence the precision of the machined surfaces.
\end{abstract}

Keywords Casting compound Ball rail system · Guideways · Dynamics

\section{Introduction}

Linear ball guideways, which are now being used more often in modern machine tools, have replaced the previously used slide guideways. A considerable disadvantage of the slide guideway system was the stick-slip phenomenon

B. Powałka $(\bowtie) \cdot$ T. Okulik

Institute of Manufacturing Engineering,

Faculty of Mechanical Engineering and Mechatronics,

West Pomeranian University of Technology, Szczecin,

Piastów 19,

70-310 Szczecin, Poland

e-mail: bartosz.powalka@zut.edu.pl

T. Okulik

e-mail: tomasz.okulik@zut.edu.pl which occurred while machining at a low feed rate $[1,2]$. This would contribute to the deterioration in the accuracy of the machine tool positioning. Fortunately, the use of ball guideways eliminated this phenomenon. The introduction of ball guideway systems improved the operating properties of the machine tool frame system by reducing the resistance to motion and increasing the permissible feed speed. It also assisted in simplifying the assembling technology compared to the slide guideway system. However, the main disadvantage of the ball guideway system is its low damping. Low damping might lead to vibrations, which may, in turn, lead to the appearance of chatter marks on the machined surface.

Machine tool constructors have tried to improve the dissipation parameters of the machine tool body system in various ways. One of the applied solutions is the use of composite materials which have high damping qualities coupled with the high specific stiffness for the construction of the machine tool body system. Such properties of the composite are achieved by using a material with high Young module and a material with high damping. Choi and Lee [3] proposed a spindle construction of carbon fibre-epoxy, which resulted in an increased natural frequency and damping than that of the steel spindle. Suh et al. [4] proposed the use of a carbon fibre composite laminate for the construction of the spindle cover. Other examples of the use of composite materials for the improvement of dynamic stiffness regarded headstock [5] and machine tool columns [6].

Kim et al. [7] designed a three-axis ultra-precision $\mathrm{CNC}$ grinding machine whose bed was made of resin concrete which contributed to the increase in the damping capacity. The effectiveness of the use of resin concrete for the construction of the bed was verified in the impulse test as well as while machining hard and brittle materials. 
The article by Kim et al. [8] presents a research on sandwich structures composed of fibre-reinforced composite materials, polymer foams and resin concrete in regard to their use for the construction of a micro-EDM machine structure. The constructed prototype was characterised by good stiffness and dissipation properties.

Another interesting way of increasing the damping in machine tools is the use of viscoelastic materials to dissipate energy $[9,10]$. The concept of viscoelastic materials is based on the use of constrained layer damping CLD [11, 12]. The vibration damping mechanism in the structures consisting of a viscoelastic layer bounded by steel sheets on both sides was examined by Chen et al. [13], who used the theory devised by Ungar [14].

Wakasawa et al. [15] examined structures packed with balls. The use of such structures allowed for a considerable increase in the damping capacity. The research took into consideration the influence of the ball size, ball arrangement as well as the degree in which they were packed together and the direction of excitation on the increase and stability of the damping capacity.

An increase in the damping capacity might also be achieved thanks to the use of cementitious materials [16]. Rahman et al. [17] investigated the influence of machining on two lathes, a ferrocement bed lathe and cast iron bed lathe, on the tool life. The improvement in tool life for the ferrocement bed lathe was attributed to its higher damping capacity.

\section{a}
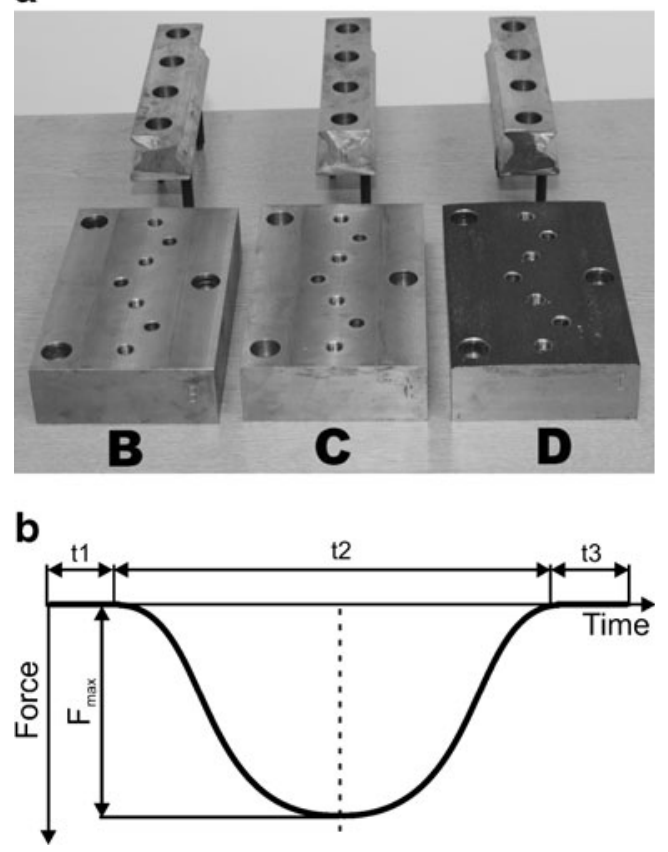

Fig. 1 a The view of the samples used in the investigation. b The characteristics of the load used in the investigation

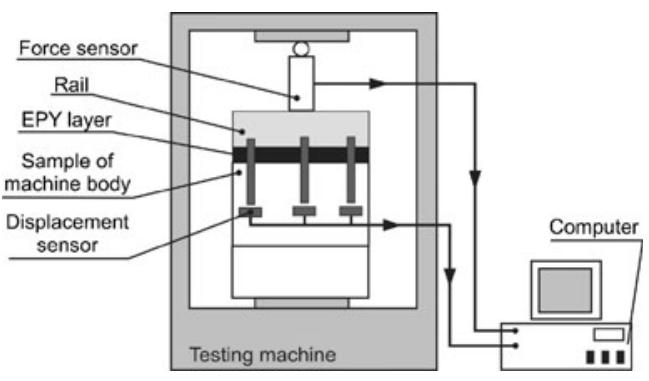

Fig. 2 The schema of the test stand for determining the deformations of the contact layer

An increase in the dissipation properties might also be achieved using polymer inserts in the construction of the guide carriage [18]. The use of a polymer impregnated concrete damping carriage was compared with a steel damping carriage. The polymer impregnated concrete damping carriage appeared to be a better solution than the steel damping carriage due to the increase in the damping capacity within the frequency range of up to $650 \mathrm{~Hz}$.

The application of the casting compound, presented in this paper, was motivated by the need to eliminate machine tool bed grinding required before guide rail assembly. The grinding operation is expensive, especially in the case of large-size machine tools. If the machine tool bed is finished by milling instead of grinding, it will increase productivity and cut production costs considerably. Milled surfaces are expected to have a lower contact stiffness than ground surfaces which is due to the lower real contact area. In this paper, a layer of EPY (tradename) casting compound [19] is applied between a guide rail and the machine tool bed as the damping material to compensate for the decrease in

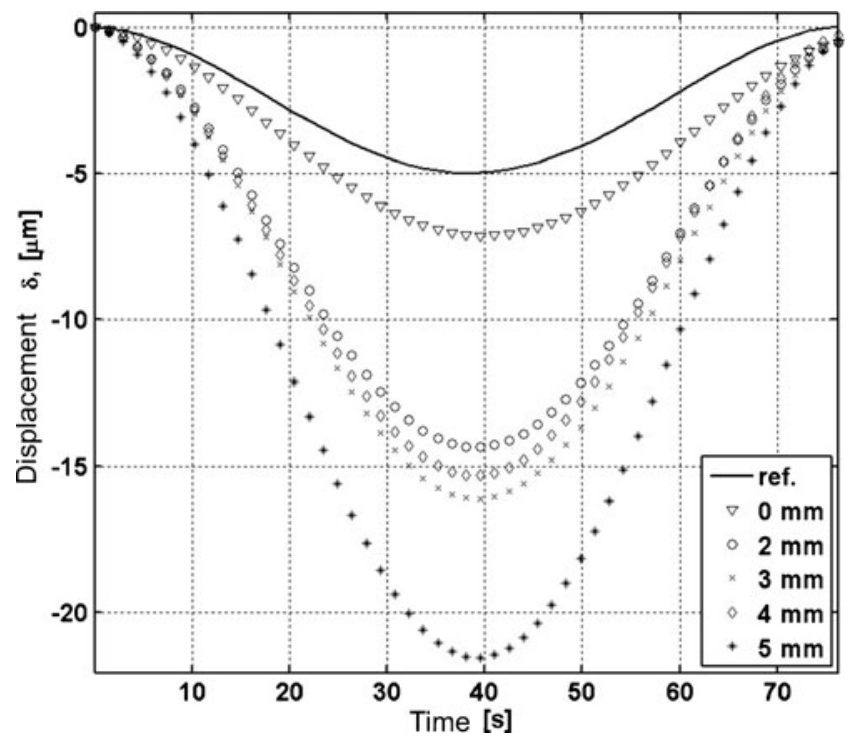

Fig. 3 The graph of the deformations registered for sample $\mathrm{C}$ by the sensor located inside the sample for the examined thicknesses of the EPY resin layer in comparison with the reference sample A 


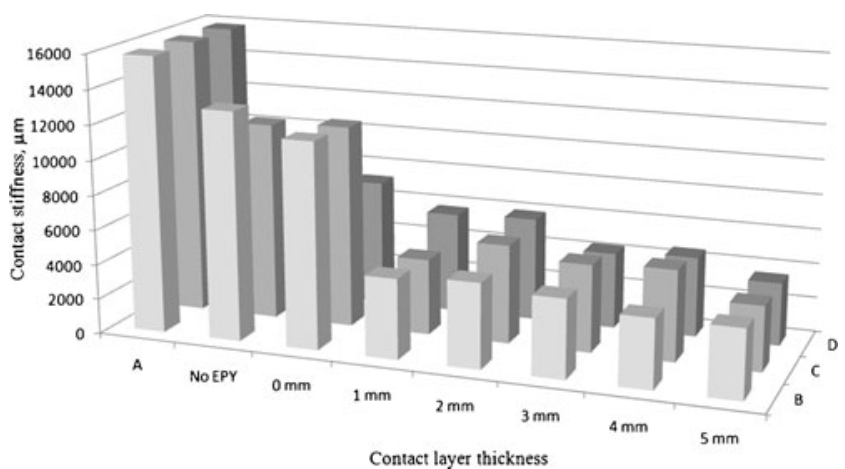

Fig. 4 Comparison of the contact stiffness for various thicknesses of the EPY resin layer

contact stiffness. EPY material is used in the seating of main engines, gears, power generators, compressors, bearings, stern tubes, tanks and many other naval machinery. First, we examined the effect of the thickness of the EPY layer and machining method on the contact stiffness and damping capacity. The obtained results were used to build a simulation model of a machine tool guideway system presented in chapter three. Model research presented in the work indicated that the use of a thin layer of EPY improves the dynamic characteristic of the machine tool. The positive influence of the use of the EPY layer obtained as a result of numerical simulations was confirmed experimentally.

\section{Static tests of the samples}

In order to verify the new method of assembling the ball guide rails with the use of a layer of EPY, it was checked how its usage influences contact stiffness and damping of the joint of the guide rail and the bed sample. Therefore, the experimental research was conducted by means of the use of three bed samples of various surface quality and roughness of the assembling surface. The surface of sample B $\left(R_{\mathrm{a}}=4.095 \mu \mathrm{m}, R_{\mathrm{z}}=21.80 \mu \mathrm{m}\right)$ was precisely milled. The

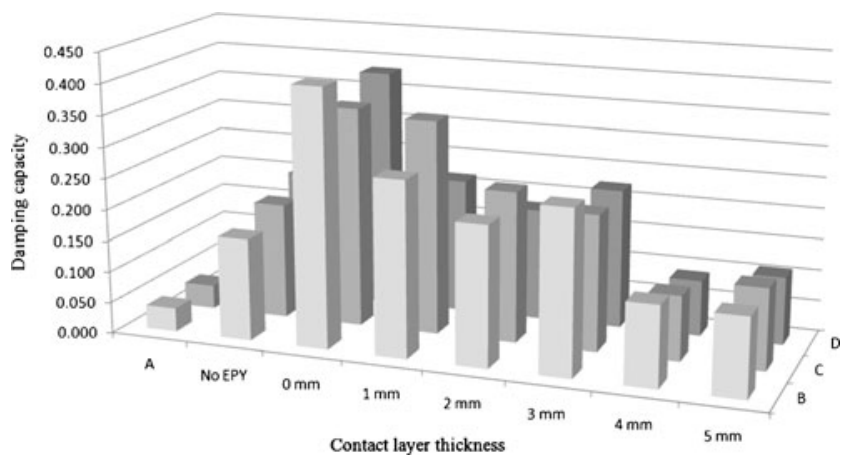

Fig. 5 Comparison of the damping capacity for various thicknesses of the EPY resin layer

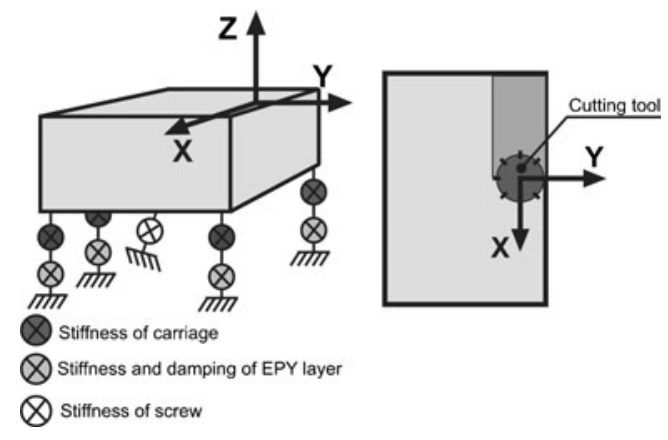

Fig. 6 Schema of the physical model of the milling table

surface of sample $\mathrm{C}\left(R_{\mathrm{a}}=8.152 \mu \mathrm{m}, R_{\mathrm{z}}=39.50 \mu \mathrm{m}\right)$ was milled with a worn cutter, while the surface quality of sample $\mathrm{D}\left(R_{\mathrm{a}}=7.898 \mu \mathrm{m}, R_{\mathrm{z}}=39.28 \mu \mathrm{m}\right)$ was like the surface of a billet. Figure 1a presents the samples used during the research. Additionally, sample $\mathrm{A}\left(R_{\mathrm{a}}=0.126 \mu \mathrm{m}\right.$, $R_{\mathrm{z}}=1.27 \mu \mathrm{m}$ ), whose surface was ground in accordance with the current assembling technology, was used in the research as a reference point for comparison.

The guide rail was fixed to the bed sample using an intermediate layer of EPY resin with the thickness of 0 to $5 \mathrm{~mm}$. The thickness of $0 \mathrm{~mm}$ was assumed to be a state in which a surplus of the thin EPY layer on the sample was squeezed out by the rail. The intermediate layer filled only the irregularities of the surface resulting from the machining.

The samples were subject to quasi static compression on the INSTRON testing machine and their forcedisplacement responses were measured. Figure 2 presents a schema of the research stand for determining the deformations in the contact layer on the joint of the rail, the EPY layer and the bed sample. Figure $1 \mathrm{~b}$ presents the characteristics of the quasi static load used during the research. The loading force increased sinusoidally to the value of $F_{\max }=80 \mathrm{kN}$, in time $\mathrm{t} 2=80 \mathrm{~s}$. Time $\mathrm{t} 1$ and $\mathrm{t} 3$ were equal to $2 \mathrm{~s}$.

Figure 3 presents the displacements registered for sample $\mathrm{C}$ by the sensor situated inside the sample for all the examined thicknesses of the EPY resin layer in comparison to the reference sample (A), which corresponded to the guide rail current assembling technology. It might be noticed on the graph that the use of the thin $(0 \mathrm{~mm})$ layer of EPY resin slightly increases the deformations of the

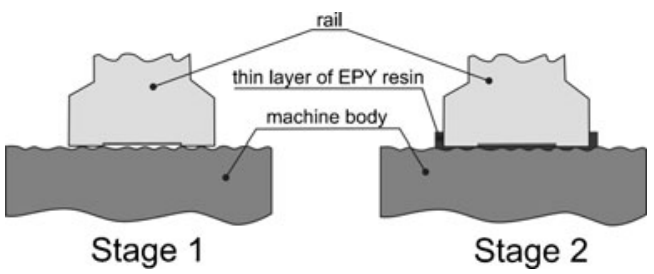

Fig. 7 Difference in the investigated models 


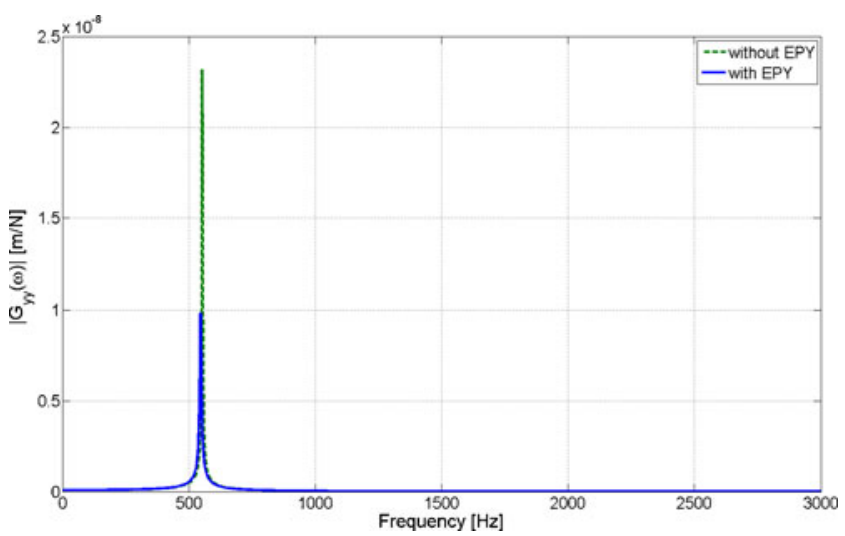

Fig. 8 Frequency response function for direction $Y$ for the analysed models

contact layer, i.e. there is a slight decrease in the static stiffness. It was found that an increased thickness, over $2 \mathrm{~mm}$ of the EPY resin layer significantly reduces the contact stiffness of the joint.

The contact stiffness and the damping capacity were determined as a result of the conducted quasi static compression tests on the bed samples. Figures 4 and 5 present the experimentally obtained coefficient values. The first bar in each graph corresponds to reference sample A machined in accordance with the technology used so far. The second bar corresponds to the samples which were not ground (B, C, D) and where the intermediate contact layer was not used. The subsequent bars correspond to the samples with an increasing thickness of the intermediate layer. It might be noticed on graph 4 that the contact stiffness of the samples without the EPY layer $(13,085 \mathrm{~N} / \mu \mathrm{m}$ - sample B) is close to the stiffness with the ' 0 ' layer $(11,789 \mathrm{~N} / \mu \mathrm{m}$ - sample B). In the case of sample $\mathrm{B}$, for which the value of the contact stiffness for the ' 0 ' thickness is the highest, a $25 \%$ decrease in stiffness was observed in comparison to sample A. Based on the comparison between Fig. 5 it might be concluded that the highest damping capacity of 0.412 appears for the

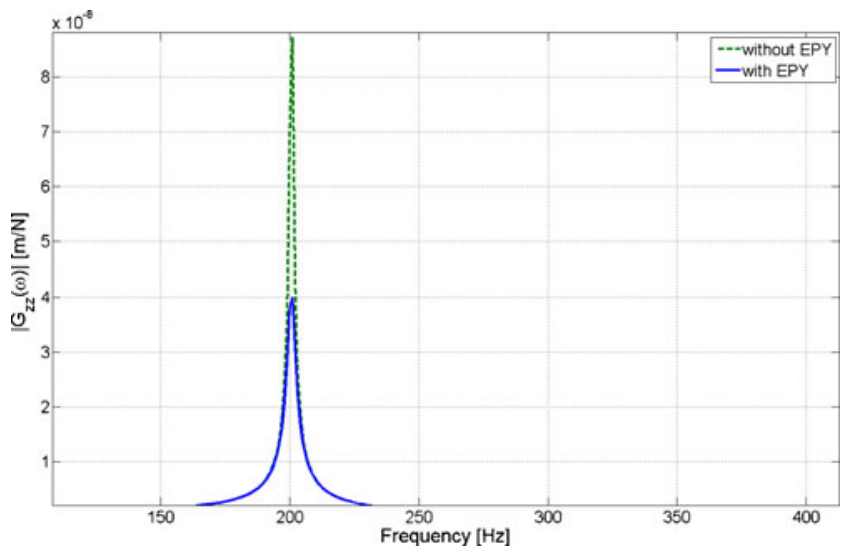

Fig. 9 Frequency response function for direction $Z$ for the analysed models

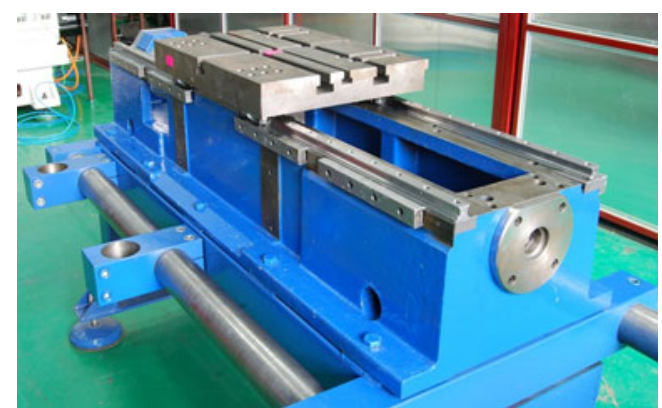

Fig. 10 The view of the stand for the milling table examination

' 0 ' thickness of EPY layer. The damping capacity for the ' 0 ' thickness of the resin layer is the highest for sample B and it is ten times higher than for sample A (0.038). Thus, the use of the thin layer of EPY on the milled surface might have a positive influence on the dynamic stiffness of the system: a slight decrease in static stiffness will be compensated by a significant increase in damping capacity.

Since the most promising results were obtained for the assembly of guide rails on the milled surface (sample B) with the use of the ' 0 ' thickness layer of EPY $(0 \mathrm{~mm})$, only this solution is compared to the traditional solution in regard to its dynamic stiffness in the simulation research.

\section{Dynamic response of the milling table model}

The contact stiffness and damping capacity obtained from the static experimental research were used to build a simulation model of the milling table mounted to the bed using guide rails. The goal of the analysis was to investigate the influence of a decrease in contact stiffness with the simultaneous increase in damping capacity on the dynamic stiffness observed for the guide rail mounted to the bed via intermediate layer of EPY resin. Figure 6 presents a schema of the physical model of the milling table together with the assumed location of the machining force. The simulation research was conducted for two variants of the guideway system assembly.

In the first simulation model, the stiffness and damping parameters corresponded to the current technology for assembling the guide rails (steel-steel contact, parameters

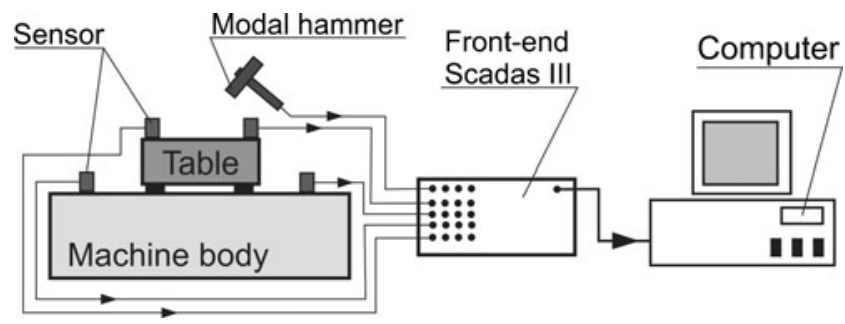

Fig. 11 Schema of the test stand used for the dynamics tests 


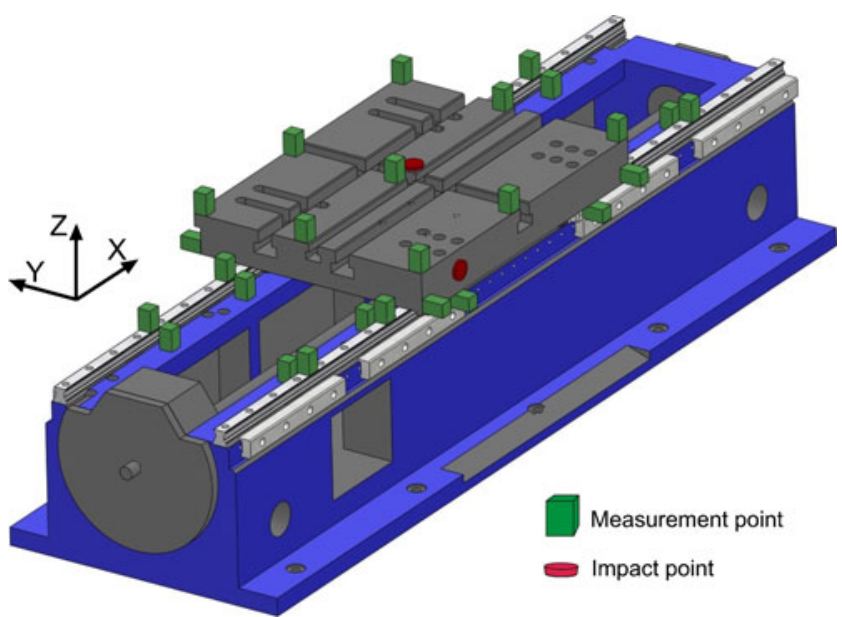

Fig. 12 The location of the measurement points in the dynamics tests

of sample A). The stiffness and damping parameters implemented in the second model tested in the simulation were those for assembling the guide rails on a thin layer of EPY (steel-EPY layer-steel contact, parameters for sample B for $0 \mathrm{~mm}$ EPY). Figure 7 schematically presents the models used in the numerical simulation.

It follows that since the machining force has a dynamic character, its dynamic characteristics play a very important role in the evaluation of machine tool performance. The dynamics of the machine tool are frequently represented in terms of frequency response functions (FRFs). The amplitude of FRFs and, in turn, the level of vibrations depends on the stiffness and damping parameters of the machine tool. Thus, the frequency response function can be used to evaluate the impact of a simultaneous decrease of the contact stiffness and an increase of damping capacity on the dynamic performance of the guide rail mounted via the intermediate layer of the EPY.

Figures 8 and 9 present the frequency response functions obtained for the simulation model of the milling table, for direction $Y$ (Fig. 8) and direction $Z$ (Fig. 9), respectively.

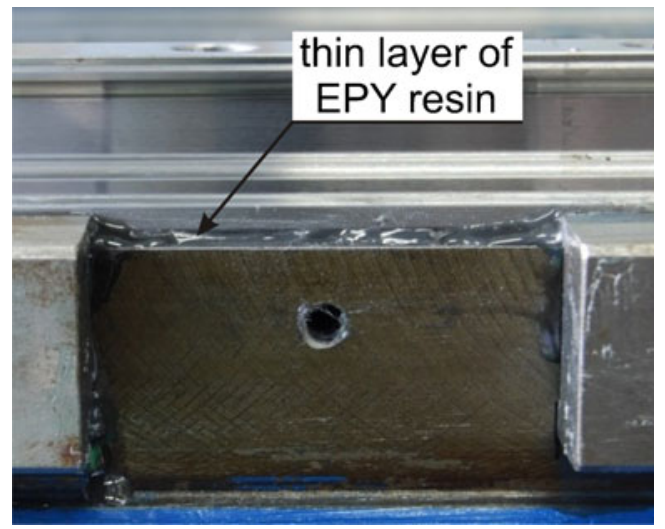

Fig. 13 A fragment of the guideway connection with a thin layer of EPY resin - the second stage of the investigation

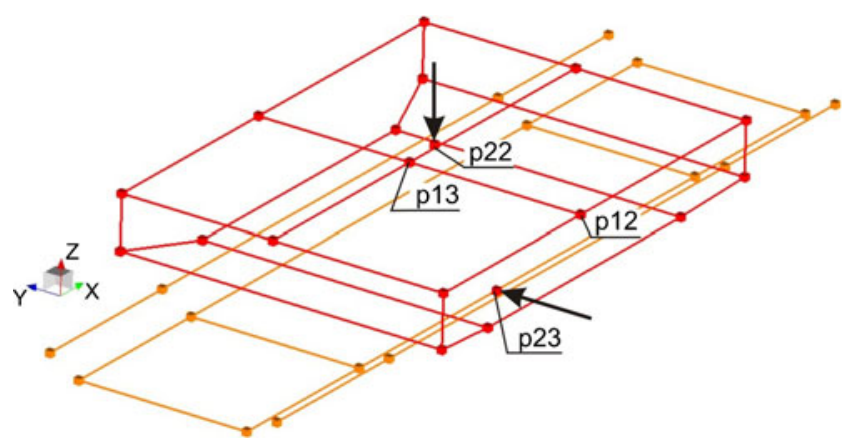

Fig. 14 The location of the points used in the comparative analysis

Direction $X$ was disregarded due to the fact that for the prepared model the stiffness in this direction depended mainly on the stiffness of the lead screw and, thus, the differences in FRF for the two considered models were negligibly small. It might be noticed on the graphs that the use of the thin layer of EPY reduces the amplitude of the system's response to the dynamic excitation. For direction $Y$, there was a decrease in the amplitude of about $58 \%$ compared to the technology for assembling guide rails used so far as well as a slight decrease in the natural frequency from the value of $553 \mathrm{~Hz}$ to the level of $547 \mathrm{~Hz}$. For direction $Z$, a decrease of about $54 \%$ in the amplitude was observed, while maintaining the same resonance frequency of the simulated system. Numerical simulation on a simple model indicated that the use of the thin layer of EPY positively influenced the dynamic stiffness of the examined guideway system.

\section{Experimental dynamic tests}

As numerical simulations presented in section 3 show there is an improvement of dynamic properties of the milling table model with its guideway when a thin layer of EPY is used. The authors were encouraged to perform an experimental verification of the obtained results. The test stand

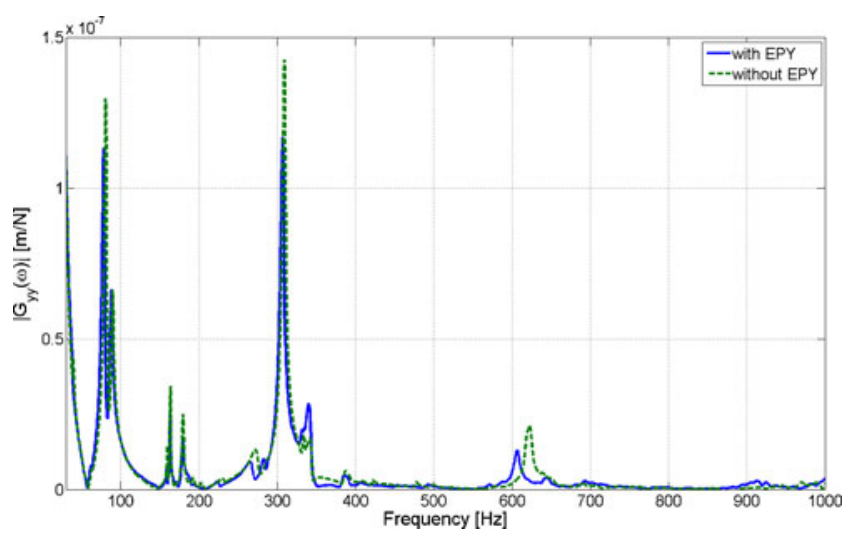

Fig. $15 \mathrm{FRF}$ at point 12 due to excitation at point 23 in direction $+Y$ 


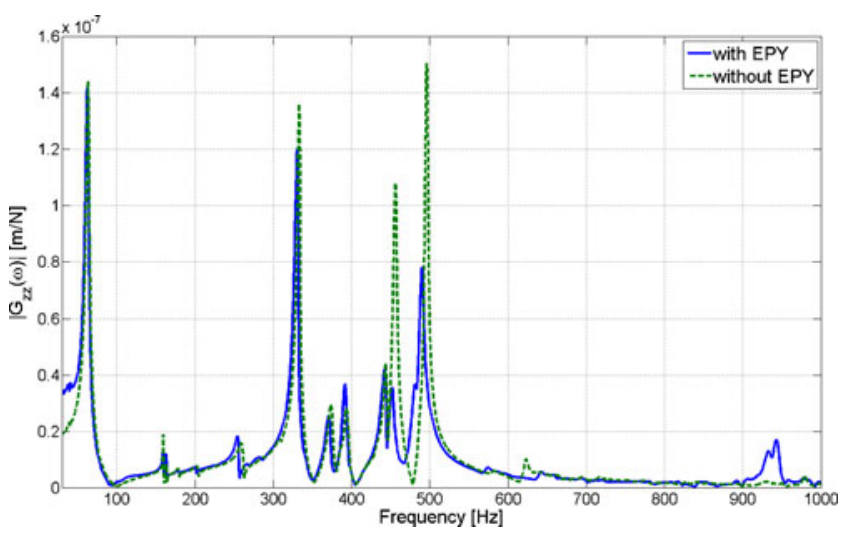

Fig. $16 \mathrm{FRF}$ at point 12 with excitation at point 22 in direction $-Z$

used for this purpose, presented in Fig. 10, is geometrically similar to the simulation model.

The stand consisted of a body element with a table supported by the linear ball bearings. The body was made of grey cast iron. The mass of the body element was ca. $314 \mathrm{~kg}$. The guideway connection was made with the use of ball guideway elements of Bosch-Rexroth which consisted of two guide rails of 25 and $1,410 \mathrm{~mm}$ in length, on which four guide carriages of 25 in length and catalogue number 1605-213-10 were moving (two carriages per each rail). The carriages of the guideway system had the preload equal to $2 \%$ of their dynamic load capacity. The dynamic load capacity of each carriage was $22,800 \mathrm{~N}$. A table, also made of grey cast iron, with a mass of $69.4 \mathrm{~kg}$ was mounted on top of the carriages. The guideway elements were founded with the use of side fixing slits in accordance to the recommendations of the guideway system producer. The screw connections of the guideway system were tightened up with a torque recommended by the producer. In addition, a turned lead screw with an external diameter of $24 \mathrm{~mm}$ and the lead of $6 \mathrm{~mm}$ was used to position the table.

Front-end Scadas III was used during the investigation of dynamics for the data acquisition. The excitation was performed by means of a Kistler modal hammer. Kistler and PCB accelerometers were used for measuring system response. The measurement data were processed with the use of LMS Test Lab software. Figure 11 presents the experimental set-up used for investigation of dynamics.

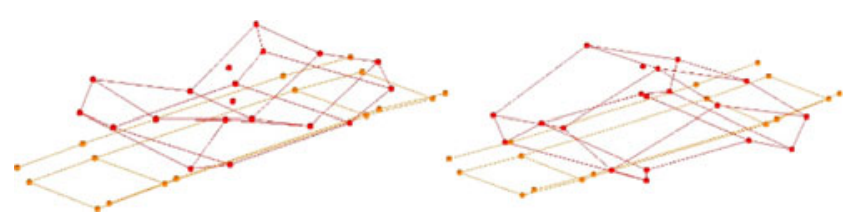

Fig. 17 Vibration mode at $455.4 \mathrm{~Hz}$

Thirty-three measurement points were located on the tested object including: eight points on the guide rails, eight points on each body element, four points on guide carriages (one on each carriage) and 13 measurement points on the table. Triaxial accelerometers were used to measure the vibration signal in each measurement point. The location of the measurement points is presented in Fig. 12.

During the investigation, the tested system was excited successively at two points. One of the excitation points was located in the central point of the table and the direction of excitation for this point corresponded to $-Z$. The second excitation point was located on the side surface of the table near the guide carriage. In this case the direction of excitation corresponded to $+Y$. The frequency response functions were determined for each of the tested directions based on 30 realizations of the excitation signal.

Investigations were conducted for the guideway with and without a thin layer of EPY (Fig. 7). First, the test stand was assembled in accordance with the assembling technology recommended by the producer of the guideway systems. Between the guide rail and the body element there was a steel-steel contact. Then the guideway system was disassembled and a thin layer of EPY was inserted between the guide rail and the body element. During the assembly, the surplus of the intermediate layer was squeezed out only to fill the irregularities on the contact surfaces of the guideway system. Figure 13 presents a fragment of the guideway connection with a thin layer of EPY used during the second stage of the investigation. Excitations and measurements points are shown in (Fig. 14).

Figure 15 shows FRF at point p12 due to excitation at point p23 (Figs. 12 and 14) within the frequency range from 30 to $1,000 \mathrm{~Hz}$. Application of the EPY results in a decrease of amplitudes in the vicinity of dominant resonances. The observed amplitude reduction varies from $18 \%$ for the dominating mode around $309 \mathrm{~Hz}$ to $40 \%$, for

Table 1 Modal parameters of the investigated object

\begin{tabular}{|c|c|c|c|c|c|c|c|c|c|c|c|c|c|c|c|c|}
\hline & \multicolumn{2}{|l|}{ Mode 1} & \multicolumn{2}{|l|}{ Mode 2} & \multicolumn{2}{|l|}{ Mode 3} & \multicolumn{2}{|l|}{ Mode 4} & \multicolumn{2}{|l|}{ Mode 5} & \multicolumn{2}{|l|}{ Mode 6} & \multicolumn{2}{|l|}{ Mode 7} & \multicolumn{2}{|l|}{ Mode 8} \\
\hline & $f_{\mathrm{n}}[\mathrm{Hz}]$ & $\zeta[\%]$ & $f_{\mathrm{n}}[\mathrm{Hz}]$ & $\zeta[\%]$ & $f_{\mathrm{n}}[\mathrm{Hz}]$ & $\zeta[\%]$ & $f_{\mathrm{n}}[\mathrm{Hz}]$ & $\zeta[\%]$ & $f_{\mathrm{n}}[\mathrm{Hz}]$ & $\zeta[\%]$ & $f_{\mathrm{n}}[\mathrm{Hz}]$ & $\zeta[\%]$ & $f_{\mathrm{n}}[\mathrm{Hz}]$ & $\zeta[\%]$ & $f_{\mathrm{n}}[\mathrm{Hz}]$ & $\zeta[\%]$ \\
\hline With EPY & 62.0 & 3.41 & 77.6 & 1.93 & 86.9 & 1.49 & 305.9 & 0.64 & 329.1 & 0.66 & 452.0 & 0.94 & 488.2 & 0.60 & 606.3 & 0.54 \\
\hline Without EPY & 62.8 & 3.23 & 80.3 & 1.71 & 88.1 & 1.71 & 308.43 & 0.57 & 332.2 & 0.55 & 455.4 & 0.47 & 495.5 & 0.31 & 621.6 & 0.47 \\
\hline
\end{tabular}


the $605 \mathrm{~Hz}$ resonance. Figure 16 presents the FRF measured at point p13 due to excitation at point p22. Similarly, an improvement of the dynamic performance of the system is observed. A significant drop of FRF amplitude has been observed in the vicinity of $500 \mathrm{~Hz}$ (about 48\%). The amplitude reduction and also a decrease of resonance frequencies can be attributed to the increased damping introduced by the application of the EPY layer. Table 1 summarizes the modal parameters of the compared configurations.

An improvement of damping ratios $(\zeta)$ is more significant for modes that exhibit relative table-machine tool bed motion. For instance, the damping ratio of Mode 6 has improved by $100 \%$. This mode is visualized in Fig. 17 .

\section{Discussion and conclusions}

The impulse tests conducted on the described test stand validate the statement that the use of a thin layer of EPY improves the dynamic performance of the object. An increase in the dynamic stiffness of the system was obtained for two tested perpendicular directions $Z$ and $Y$. An increase in the dynamic stiffness resulting from the increased damping capacity in the EPY layer occurred in the areas of dominant resonances. These resonances are responsible for the dynamics of the tested system. This means that the decrease in stiffness resulting from the use of the thin layer of EPY is compensated with a significant increase in damping capacity. The increase might be caused by the convection of the mechanical energy of vibrations into the thermal energy on the resin-steel contact $[12,13]$ or by an increase of the effective contact surface as the resin fills all the irregularities of the connected surfaces [19]. The explanation for the complex mechanism of the damping of vibrations in the thin layer of EPY resin is beyond the range of this work.

The presented proposal for the assembly of guideway systems that make use of a layer of EPY resin might be very attractive from the practical point of view. The attractiveness results from the reduction in the costs of preparing the assembled surfaces for the guide rails by eliminating the expensive grinding operation. An undeniable advantage of the method is also its simplicity as it does not require the construction of any special equipment. The solution presented in the work is the subject of patent application no P388153 in the Patent Office of the Republic of Poland.

Acknowledgement The work was financed from the resources for science in the years $2009-2010$ as a research project no. N503 174637.
Open Access This article is distributed under the terms of the Creative Commons Attribution Noncommercial License which permits any noncommercial use, distribution, and reproduction in any medium, provided the original author(s) and source are credited.

\section{References}

1. Bell R, Burdekin M (1969-70) A study of stick-slip motion of machine tool feed driver. Proceedings of the Institution of Mechanical Engineers 184:543-560

2. Marui E, Endo H, Hashimoto M, Kato S (1996) Some considerations of slideway friction characteristics by observing stick-slip vibration. Tribol Int 29:251-262

3. Choi JK, Lee DG (1997) Manufacture of a carbon fibre-epoxy composite spindle bearing system for a machine tool. Compos Struct 37:241-251

4. Suh JD, Chang SH, Lee DG, Choi JK, Park BS (2001) Damping characteristics of composite hybrid spindle covers for high speed machine tools. J Mater Process Technol 113:178-183

5. Chang SH, Kim PJ, Lee DG, Choi JK (2001) Steel-composite hybrid headstock for high-precision grinding machine. Compos Struct 53:1-8

6. Lee DG, Chang SH, Kim HS (1998) Damping improvement of machine tool columns with polymer matrix fiber composite material. Compos Struct 43:155-163

7. Kim HS, Jeong KS, Lee DG (1997) Design and manufacture of a three-axis ultra-precision $\mathrm{CNC}$ grinding machine. J Mater Process Technol 71:258-266

8. Kim DI, Jung SC, Lee SH, Chang SH (2006) Parametric study on design of composite foam resin concrete sandwich structures of precision machine tool structures. Compos Struct 75:408-414

9. Marsh ER, Slocum AH (1996) An integrated approach to structural damping. Precis Eng 18:103-109

10. Bamberg E, Slocum AH (2002) Concrete-based constrained layer damping. Precis Eng 26:430-441

11. Plass HJ (1957) Damping vibrations in elastic rods and sandwich structures by incorporation of additional viscoelastic material. In: Proceedings of Third Midwestern Conference on Solid Mechanics, pp 388-392

12. Ross D, Ungar E, Kerwin EM (1959) Damping of plate flexural vibrations by means of viscoelastic laminae. In: Ruzicka JE (ed) Structural Damping. Colloquium ASME, Atlantic City

13. Chen YS, Hsu TJ, Chen SI (1991) Vibration damping characteristics of laminated steel sheet. Metallurgical Trans A 22A:653-656

14. Ungar E (1979) In: L.L. Beranek (ed.) Noise and vibrations control. McGraw-Hill, Inc., New York

15. Wakasawa Y, Hashimoto M, Marui E (2004) The damping capacity improvement of machine tool structures by balls packing. Intern J Machine Tools and Manufacture 44:1527-1536

16. Rahman M, Mansur MA (1993) Evaluation of a lathe with ferrocement bed. Annals of the CIRP 42:437-440

17. Rahman M, Mansur MA, Lau SH (2001) Tool wear study in a lathe made of cementitious material. J Mater Process Technol 113:317-321

18. Rahman M, Mansur MA, Lee LK, Lum JK (2001) Development of polymer impregnated concrete damping carriage for linear guideways for machine tools. Intern $\mathrm{J}$ Machine Tools and Manufacture 41:431-441

19. Grudziński K, Jaroszewicz W (2004) Seating of machines and devices on foundation chocks cast of EPY resin compound. Zapol, Szczecin 